Supporting information

\title{
Surfactantless Synthesis of Multiple Shapes of Gold Nanostructures and Their Shape-Dependent SERS Spectroscopy
}

\author{
Tie Wang, Xiaoge Hu, and Shaojun Dong ${ }^{*}$
}

State Key Laboratory of Electroanalytical Chemistry, Changchun Institute of Applied Chemistry, Chinese Academy of Sciences, Changchun, Jilin 130022, People's Republic of China, and Graduate School of the Chinese Academy of Sciences, Beijing, 100039, People's Republic of China

Side view

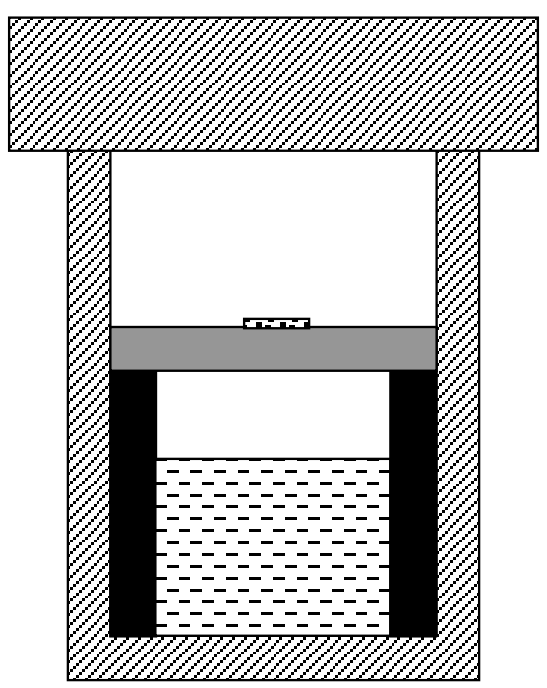

Planform

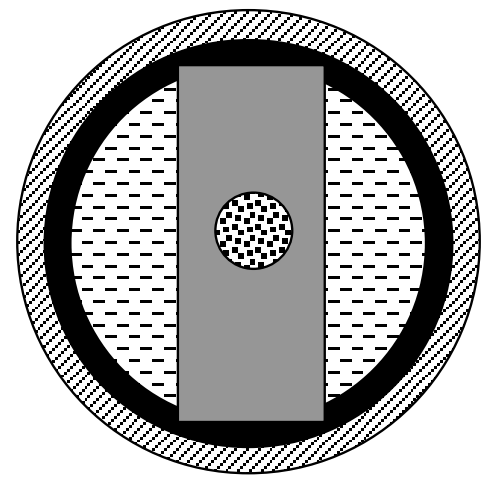

Figure S1. Schematic diagram of the experimental setup $\mathbb{Z}$, autoclave $\square$, silicon slide;

\footnotetext{
*Corresponding author: Tel: +86-431-5262101; Fax: +86-431-5689711; E-mail: dongsj@ ciac.jl.cn
} 